\title{
A Dual-Band Single-Feed Switched Beam Antenna for WLAN
}

\author{
Pichaya Chaipanya, Pawarit Rattanakriengkai, Pijitra Potup and Laliphat Lapourailers
}

\begin{abstract}
This article presents the dual-band of a single patch antenna that can operate at a frequency of 2.47 to $5.04 \mathrm{GHz}$, which is available in WLANs (IEEE 802.11). The beam pattern of the antenna can be switched by changing the position of shortedcircuit points at each edge of the antenna. The advantage of the proposed antenna is that it is a simple structure which is small in size, weighs little and has an easily adjustable beam. In addition, the antenna is tested under real circumstances using the existing WLAN infrastructure. The results confirm that the signal strength can be improved when the proposed switched beam antenna is utilized.
\end{abstract}

Keywords - dual-band, single-feed, switched-beam antenna, shorted circuit, signal strength

\section{INTRODUCTION}

$\mathbf{N}$ OWADAYS, wireless communication technologies are a part of daily life. The demand for wireless communication has rapidly increased. Therefore, the wireless system needs a higher frequency spectrum to manage this tremendous demand. However, the available frequency spectrum is currently limited. One technique that can increase the wireless system capacity without changing the frequency spectrum is a smart antenna technique [1]. The smart antennas are constituted by multiple element antennas accompanied by suitable signal processing units, either at the transmitter or receiver side of a communication link. The term beamforming means pointing the antenna beam towards a desired user and nulls or low side lobes towards interfering sources. According to this, the smart antennas are capable of considerably improving the quality of signal transmission in a multi user environment.

Wireless Local Area Network (WLAN) is one of a category of wireless communications that is used extensively. The IEEE $802.11 \mathrm{~b} / \mathrm{g}$ standards use the 2.4 frequency band while the IEEE 802.11a standard uses the $5 \mathrm{GHz}$ frequency band. IEEE $802.11 \mathrm{n}$ standard uses a dual frequency band $(2.4 \mathrm{GHz}$ and $5 \mathrm{GHz}$ ). To support all IEEE 802.11 standards and increase the capacity of the systems, many types of switched beam antenna are proposed. The antenna that is a simple structure, small in size and suitable for mobile terminals is the most interesting.

There are some examples from literature concerning a dual band switched beam antenna using a single element. The work presented in [2] has shown that an antenna can operate at 2.45

This work was supported by the Faculty of Engineering, Srinakharinwirot University, Thailand [364/2015, 2015].

Authors are with Department of Electrical Engineering, Srinakharinwirot University, Nakhon Nayok, Thailand (e-mail: pichayac@g.swu.ac.th, tong_7484@hotmail.com,_dhko8b@hotmail.com,_mamiiw2379@ hotmail.com).
$\mathrm{GHz}$ and $5.8 \mathrm{GHz}$. The beam pattern can switch in two directions by changing the position of the feeding point, likewise in the work of [3], in which the antenna operated at $2.4 \mathrm{GHz}$ and 5.2 GHz. Also the works presented in [4-6] have proposed a dual band, low-profile, switched beam square loop antenna with capacitively coupled feeds, a dual-band lowprofile capacitively coupled beam-steerable square-loop antenna and a low-profile switched-beam dual-band capacitively coupled square loop antenna. The antennas were developed to operate at $3.1 \mathrm{GHz}$ and $3.8 \mathrm{GHz}$ frequency bands for the work of [4] $3.8 \mathrm{GHz}$ and $4.7 \mathrm{GHz}$ frequency bands for the work of [5] and $4.1 \mathrm{GHz}$ and $5.2 \mathrm{GHz}$ frequency bands for the work of [6]. The antennas can steer beams in four different quadrants using four vertical feeding probes by four rectangular feeding patches. However, beams can also be switched by changing the feeding point. This is not considered practical as the feeding network is relatively complicated. The works of [7-8] have revealed a low profile antenna which is capable of beam switching in two directions and eight directions, respectively. They antenna is a simple structure using a single-layer printed circuit board. Beams can be switched by a shorted circuit at each edge of the antenna. Nevertheless, they can operate only on the single frequency band. Therefore, this article proposes a dual-band switched beam antenna with the antenna designed to support WLAN frequency bands. Moreover, it's a low profile structure, only using a single feed. It is a simple beam, switchable by a shorted circuit at each edge of the patch antenna.

The rest of this article is as follows. After a brief introduction, configuration of the proposed antenna is discussed in section II. The simulation and experimental results are revealed and analyzed in section III. Next, the measured results obtained from testing the fabricated antenna under real circumstances, having a WLAN operation are shown in section IV. Finally, section V concludes the article.

\section{CONFIGURATION OF THE ANTENNA}

In this article, the advantages of the antenna from the work presented in [2] are adopted due to its simplicity and its ability to operate on a dual band. However, beam switching is simplified using only a single feeding point. From the work of [2] the square patch of each frequency is sized by

$$
\lambda_{d}=\frac{\lambda}{\sqrt{\varepsilon_{r}}}
$$

where $\varepsilon_{r}$ is the dielectric constant of substrate. Therefore, there are two patches which operate two frequencies on a single antenna. Two microstrip transmission lines are shorted between these two patches, the length and width of lines are $a$ and $b$, respectively. According to this, the size and structure of 
the proposed antenna in this article is also based on the work of [2]. However, the size of patches, $a$ and $b$ are varied due to changing the position of the feeding point and the thickness of the substrate. Then antenna configuration of the completed design is shown in Fig. 1 in which a patch, working at $5 \mathrm{GHz}$, has a width of $30.32 \mathrm{~mm}$, a patch working at $2.45 \mathrm{GHz}$ which has a width of $89.02 \mathrm{~mm}, a$ of $2.59 \mathrm{~mm}, b$ of $8.45 \mathrm{~mm}$ and a substrate thickness of $1.6 \mathrm{~mm}$. To switch beam pattern, each edge of the antenna has a shorted circuit, three shorted positions of each edge are $30 \mathrm{~mm}$ apart. In Fig. 1, right edge and left edge of the patch are shorted circuit to beam steerable.

In the next Section, the results in term of $S_{11}$ and radiation patterns of dual-frequency are revealed. The results from the experimental data are compared with the ones obtained from simulation.

\section{THE SIMULATION AND EXPERIMENTAL RESULTS}

The designed antenna is simulated using CST Microwave Studio at $2.45 \mathrm{GHz}$ and $5 \mathrm{GHz}$, the structure is shown in Fig. 2. $S_{11}$, from simulation, is shown in Fig. 3 with the lowest value at $2.47 \mathrm{GHz}$ and $5.04 \mathrm{GHz}$ are $27.98 \mathrm{~dB}$ and $24.88 \mathrm{~dB}$, respectively. As we can see, the center frequencies are slightly shifted. Next, the radiation pattern can be separated into two cases providing two different directions. First, the beam pattern can be switched by a shorted circuit on the left and right edges of the antenna, namely case $\mathrm{A}$. The other is case $\mathrm{B}$

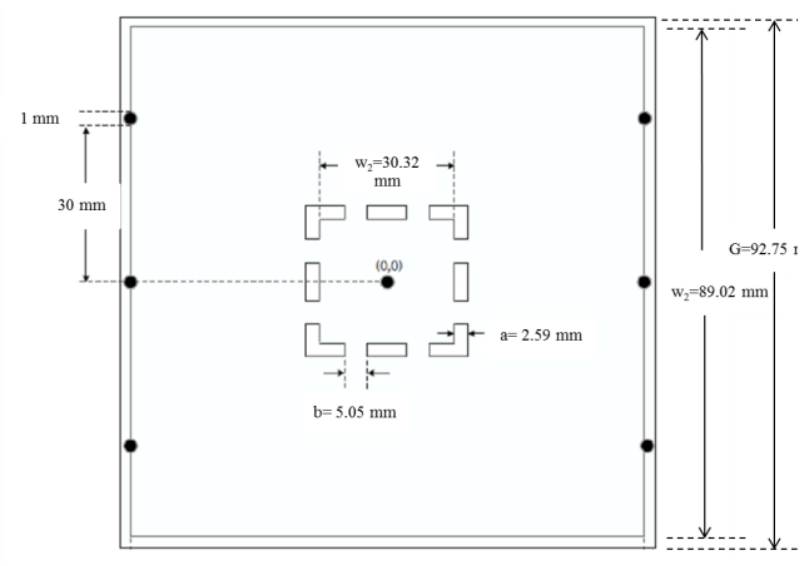

Fig. 1. The antenna configuration.

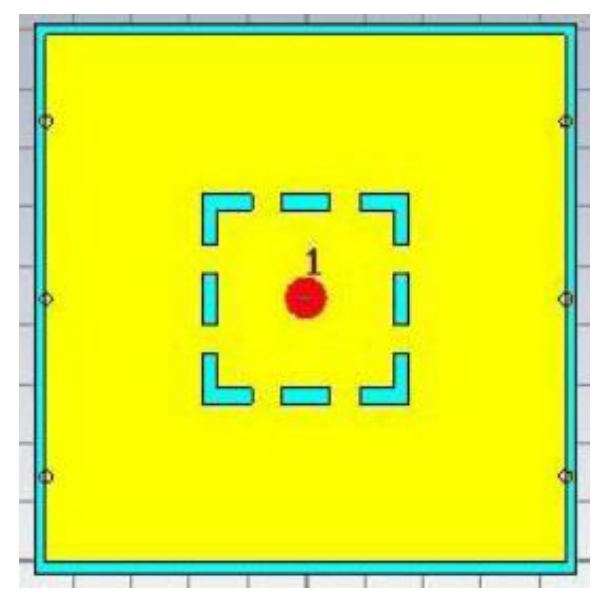

Fig. 2. The structure of antenna from simulation. which is a shorted circuit on the top and bottom edges of the antenna. The radiation patterns at $2.47 \mathrm{GHz}$ and $5.04 \mathrm{GHz}$ of case A are shown in Fig. 4 (a). Also, the radiation patterns at $2.47 \mathrm{GHz}$ and $5.04 \mathrm{GHz}$ of case B are shown in Fig. 4 (b). As we can see, when the edges, which has a low current distribution of the antenna, are a shorted circuit, the beam pattern is switched in different directions of shorted-positions. In addition, radiation patterns of case $A$ and case $B$ are similar. This is due to the configuration of the antenna being symmetrical. However, the main beam directions are different because of the different positions of the shorted circuit. Therefore, beam pattern of the proposed antenna can be switched in two different directions, the directions of case $\mathrm{A}$ are $90^{\circ}$ and $270^{\circ}$ while the directions of case $\mathrm{B}$ are $0^{\circ}$ and

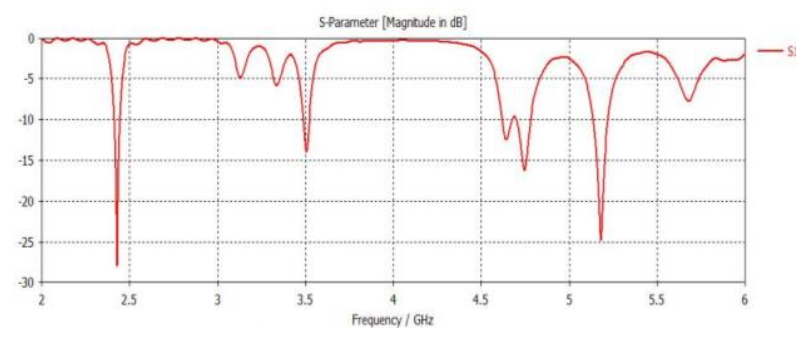

Fig. 3. $\mathrm{S}_{11}$ from simulation.

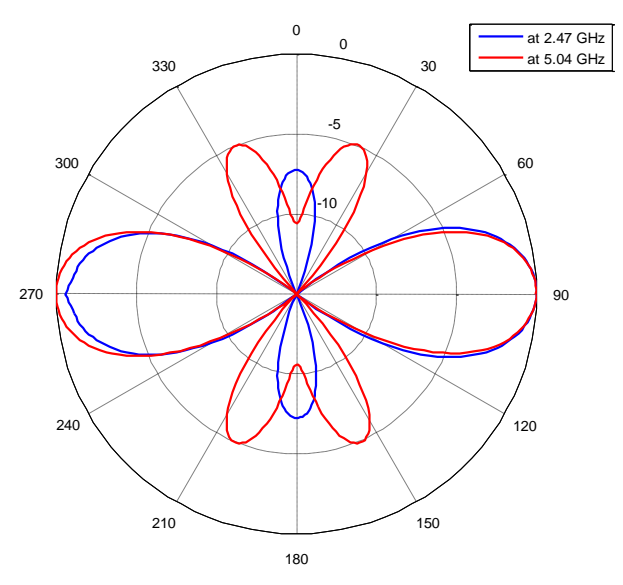

(a)

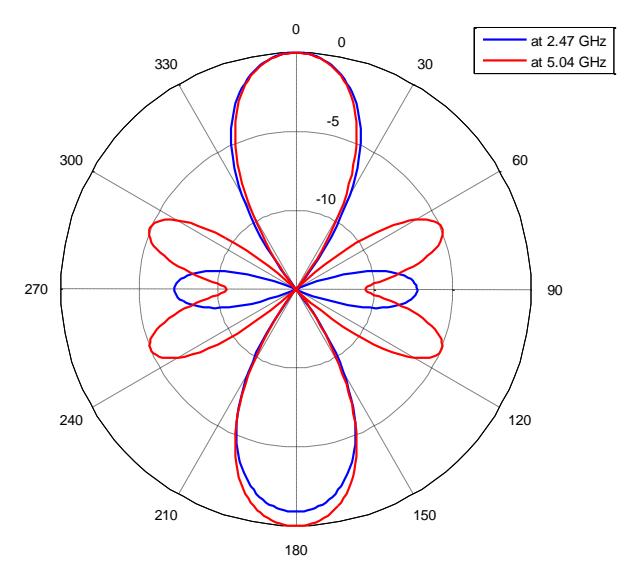

(b)

Fig. 4. The radiation patterns from simulation at $2.47 \mathrm{GHz}$ and 5.04 $\mathrm{GHz}$ of (a) case A and (b) case B. 
$180^{\circ}$.

Next, the proposed antenna is constructed and tested to demonstrate its beam steering capability. The designed antenna is fabricated using a single-layer printed circuit board, using FR4-substrate with a dielectric constant of 4.5 as the structure of case A shows in Fig. 5. The SMA connector is attached from one side through another side at the patch center. $S_{11}$ and radiation patterns are measured using a network analyzer. $\mathrm{S}_{11}$ from measurement is shown in Fig.6. It is $13.025 \mathrm{~dB}$ and $20.868 \mathrm{~dB}$ at $2.47 \mathrm{GHz}$ and $5.05 \mathrm{GHz}$, respectively. The radiation patterns at $2.47 \mathrm{GHz}$ and $5.04 \mathrm{GHz}$ in case $\mathrm{A}$ are shown in Fig. 7(a). Also, the radiation patterns at $2.47 \mathrm{GHz}$ and $5.04 \mathrm{GHz}$ in case B are shown in Fig. 7 (b). As we can see, the simulation results have a good agreement with the ones from the measurement. Moreover, $S_{11}$ is moderately comparable and beam directions are also relatively similar. The average measured gains for the two cases are $2.6 \mathrm{dBi}$ and $7.5 \mathrm{dBi}$ for frequencies of $2.47 \mathrm{GHz}$ and $5.04 \mathrm{GHz}$, respectively. However, the sidelobes of $5.04 \mathrm{GHz}$ are slightly different. This may be caused by a manufacturing error. However, the proposed antenna is able to confirm its beam switching capability.

The next section focuses on confirming the performance of the proposed switched beam antenna. The antenna is tested under real circumstances in transmitting real WLANs signals comparing that with the use of omnidirectional antenna and the antenna which is embedded in a computer notebook.

\section{THE PERFORMANCE FROM FABRICATED ANTENNA}

The fabricated antenna is tested under real circumstances in existing WLAN operations at the 1st level of the Department

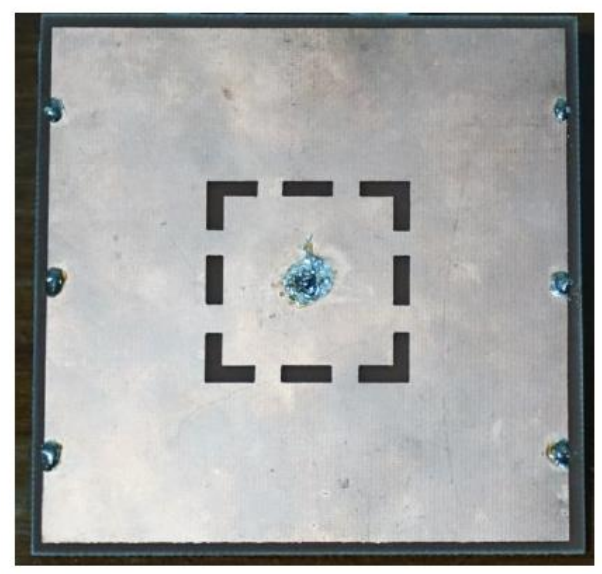

Fig. 5. The fabricated antenna.

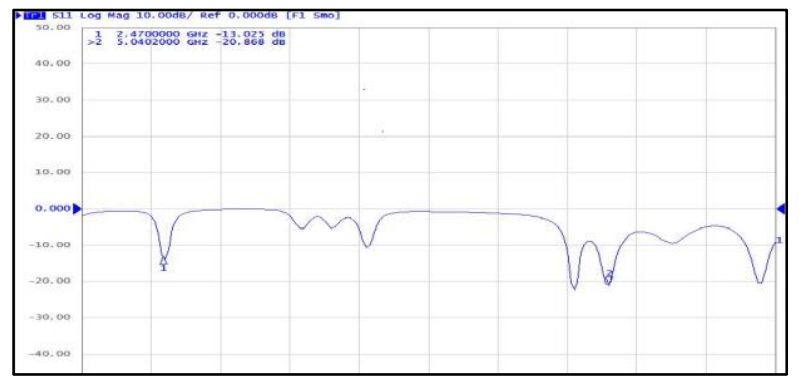

Fig. 6. $\mathrm{S}_{11}$ of fabricated antenna.

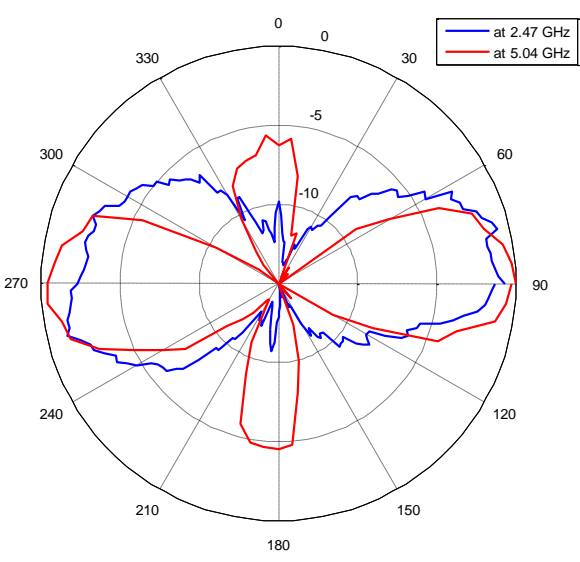

(a)

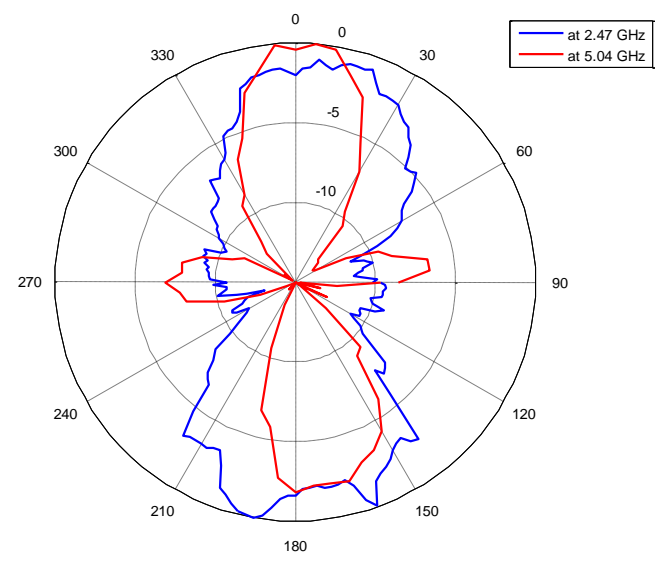

(b)

Fig. 7. The radiation patterns from experimental at $2.47 \mathrm{GHz}$ and 5.04 $\mathrm{GHz}$ of (a) case A and (b) case B.

of Electrical Engineering, Srinakharinwirot University. The layouts of testing at this department are shown in Fig. 8 and Fig. 9 for frequencies of $2.47 \mathrm{GHz}$ and $5.04 \mathrm{GHz}$, respectively. Please note that the access point which operates at $5 \mathrm{GHz}$ is limited. Therefore, positions of testing for both frequencies are different. The signal strength recorded in the computer notebook is shown in Fig. 10. The measured signal strength at $2.47 \mathrm{GHz}$ is shown in Table I. There are 15 points of measurement (1-15) which were chosen as being measuring locations as is shown in Fig. 8. The comparison between using the proposed antenna, omnidirectional antenna and embedded antenna is revealed. The value in bold represents the maximum signal strength in each case. As we can see, the signal strength with the proposed antenna is generally stronger than with other antennas. A few positions have lower signal strength by employing an omnidirectional antenna because of the position of the access point being located between main beams in the two cases. However, utilization of the proposed antenna in most positions provide a higher signal strength than the others. In addition, the signal strength of each channel that operates in Thailand is measured. Also, the comparison of three antenna types is shown in Table II. As we can see, signal strength is always higher than the others when the proposed antenna is utilized. Moreover, the signal power at $2.47 \mathrm{GHz}$ and the signal power of each channel that operates in Thailand 

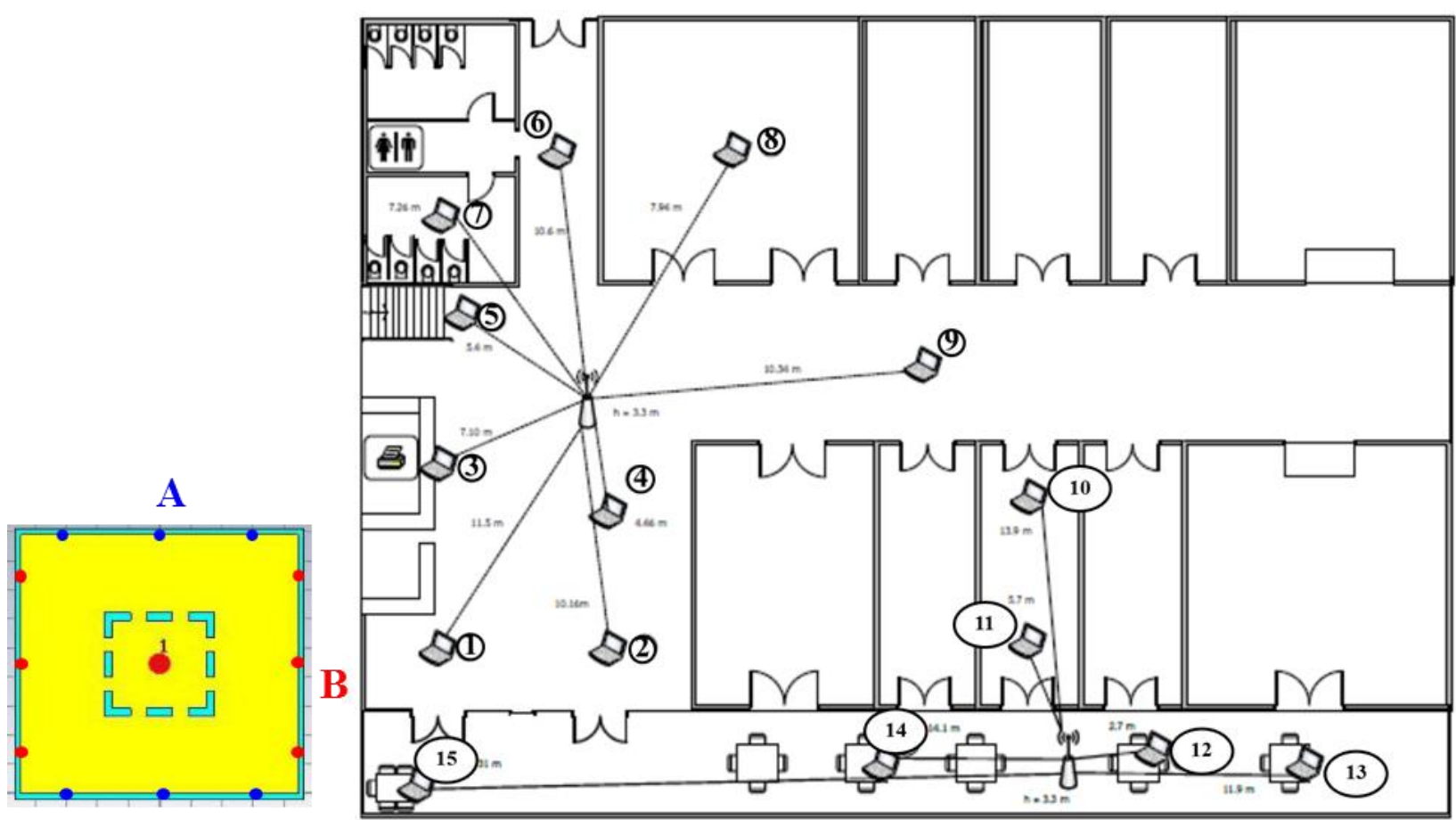

Fig. 8. The layout of testing at the department of electrical for frequencies of $2.47 \mathrm{GHz}$.
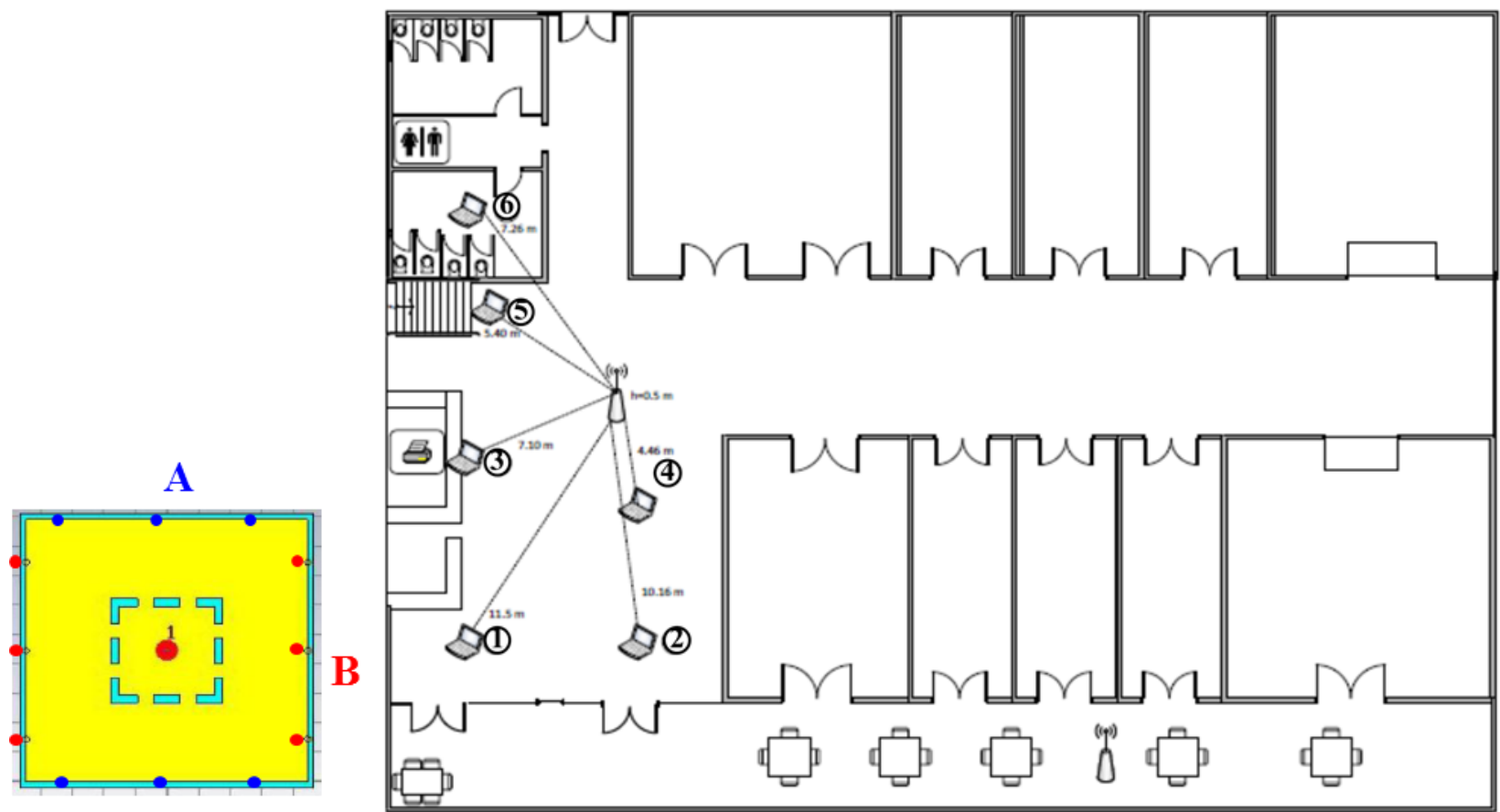

Fig. 9. The layout of testing at the department of electrical for frequencies of $5.04 \mathrm{GHz}$.

are measured using spectrum analyzer to confirm the performance of the proposed switched beam antenna as shown in Fig. 11. In the measurement setup, case A means that main beam of the proposed antenna is directed to the transmitted antenna which is connected with signal generator. Also, side lobe of the proposed antenna is directed to the transmitted antenna that prefers to case B. The comparison between using the proposed antenna and omnidirectional antenna are shown in Table III. The results can confirm that the proposed antenna provides a higher signal strength than the omnidirectional antenna when main beam is directed to the transmitter. Moreover, signal strength at $5.04 \mathrm{GHz}$ is also measured and compared with the one obtained from an omnidirectional antenna. The results from laptop are shown in Table IV. There are 6 points of measuring (1-6) which are chosen as being measuring locations, as is shown in Fig. 9. Signal strength, which is measured with each channel, are compared and shown in Table V. Please note that the signal strength when 


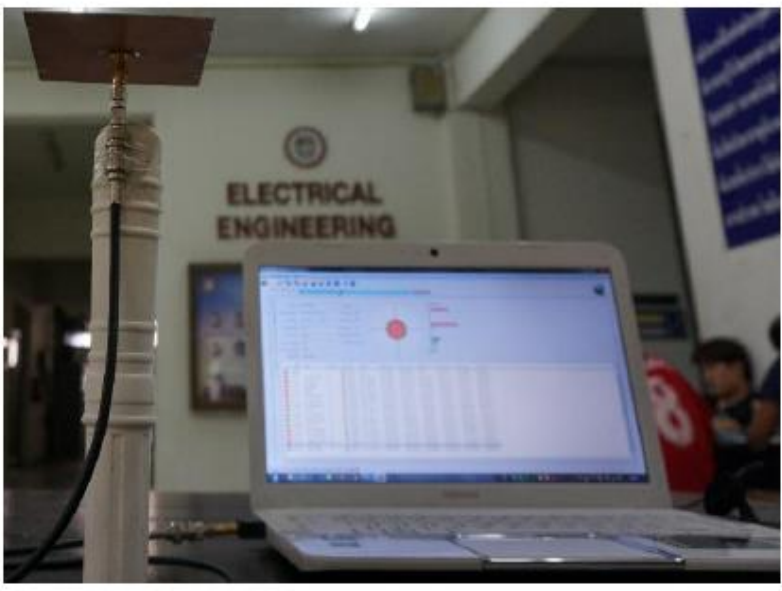

Fig. 10. Measurement setup under existing WLAN infrastructure.

TABLE I

The Measured Signal StREnGth AT $2.47 \mathrm{GHz}$

\begin{tabular}{|c|c|c|c|c|}
\hline \multirow{3}{*}{ Position } & \multicolumn{4}{|c|}{ Signal Strength } \\
\hline & \multirow{2}{*}{$\begin{array}{l}\text { embedded } \\
\text { antenna }\end{array}$} & \multirow{2}{*}{$\begin{array}{l}\text { omni- } \\
\text { directional } \\
\text { antenna }\end{array}$} & \multicolumn{2}{|c|}{ The proposed antenna } \\
\hline & & & case $\mathrm{A}$ & case B \\
\hline 1 & -73 & -65 & -61 & -63 \\
\hline 2 & -76 & -61 & -63 & -59 \\
\hline 3 & -71 & -63 & -62 & -65 \\
\hline 4 & -64 & -57 & -58 & -55 \\
\hline 5 & -74 & -67 & -69 & -69 \\
\hline 6 & -70 & -54 & -57 & -53 \\
\hline 7 & -88 & -67 & -69 & -69 \\
\hline 8 & -80 & -75 & -73 & -75 \\
\hline 9 & -78 & -61 & -61 & -63 \\
\hline 10 & -73 & -63 & -65 & -62 \\
\hline 11 & -72 & -53 & -55 & -52 \\
\hline 12 & -55 & -47 & -47 & -51 \\
\hline 13 & -49 & -39 & -37 & -39 \\
\hline 14 & -63 & -49 & -49 & -52 \\
\hline 15 & -69 & -65 & -64 & -66 \\
\hline
\end{tabular}

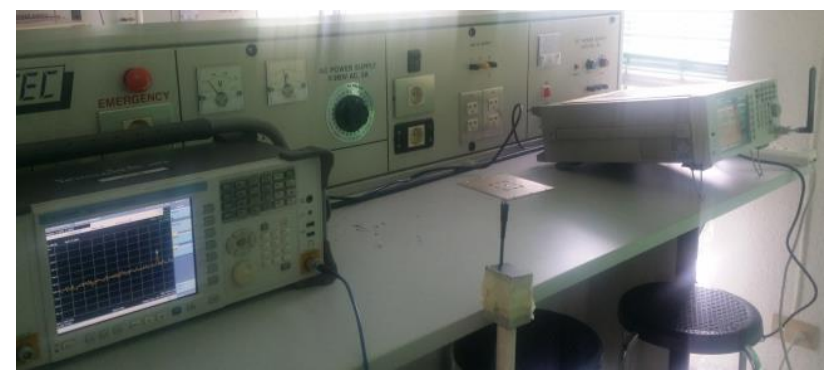

Fig. 11. Measurement of signal power using spectrum analyzer.

employing an embedded antenna on a computer notebook cannot be compared due to the embedded antenna only being able to operate on a single band at $2.45 \mathrm{GHz}$. As we can see, the proposed antenna always provides a higher signal strength compared with the one obtained from an omnidirectional antenna. Also, the results form spectrum analyzer at $5.04 \mathrm{GHz}$ and each channel that operates in Thailand are shown in Table VI. As we can see, the proposed antenna provides a higher signal strength than the other. Therefore, we can confirm that the proposed switched beam antenna improves the performance of the systems in dual frequency bands.
TABLE II

The Measured Signal Strength of EACH ChannEl AT $2.47 \mathrm{GHz}$

\begin{tabular}{|c|c|c|c|c|}
\hline \multirow{3}{*}{$\begin{array}{c}\text { Channel } \\
(\mathrm{GHz})\end{array}$} & \multicolumn{4}{|c|}{ Signal Strength } \\
\hline & \multirow{2}{*}{$\begin{array}{l}\text { embedded } \\
\text { antenna }\end{array}$} & \multirow{2}{*}{$\begin{array}{l}\text { omni- } \\
\text { directional } \\
\text { antenna }\end{array}$} & \multicolumn{2}{|c|}{ The proposed antenna } \\
\hline & & & case $\mathrm{A}$ & case B \\
\hline $\begin{array}{c}1(2.401- \\
2.423)\end{array}$ & -47 & -29 & -29 & -27 \\
\hline $\begin{array}{c}2(2.406- \\
2.428)\end{array}$ & -49 & -33 & -24 & -27 \\
\hline $\begin{array}{c}3(2.411- \\
2.433)\end{array}$ & -47 & -35 & -27 & -27 \\
\hline $\begin{array}{c}4(2.416- \\
2.438)\end{array}$ & -46 & -31 & -29 & -26 \\
\hline $\begin{array}{c}5(2.421- \\
2.443)\end{array}$ & -45 & -33 & -29 & -30 \\
\hline $\begin{array}{c}6(2.426- \\
2.448)\end{array}$ & -40 & -33 & -28 & -31 \\
\hline $\begin{array}{c}7(2.431- \\
2.453)\end{array}$ & -40 & -33 & -26 & -29 \\
\hline $\begin{array}{c}8(2.436- \\
2.458)\end{array}$ & -42 & -35 & -29 & -29 \\
\hline $\begin{array}{c}9(2.441- \\
2.463)\end{array}$ & -40 & -33 & -29 & -29 \\
\hline $\begin{array}{c}10(2.446- \\
2.468)\end{array}$ & -40 & -31 & -31 & -30 \\
\hline $\begin{array}{c}11(2.451- \\
2.473)\end{array}$ & -48 & -33 & -26 & -28 \\
\hline
\end{tabular}

TABLE III

FREQUENCY SPECTRUM AT 2.47 GHZ AND EACH CHANNEL USING SPECTRUM ANALYZER

\begin{tabular}{|c|c|c|c|}
\hline \multirow{3}{*}{$\begin{array}{l}\text { Frequency } \\
\quad(\mathrm{GHz})\end{array}$} & \multicolumn{3}{|c|}{ Signal Power $(\mathrm{dBm})$} \\
\hline & \multirow{2}{*}{$\begin{array}{l}\text { omni- } \\
\text { directional } \\
\text { antenna }\end{array}$} & \multicolumn{2}{|c|}{ The proposed antenna } \\
\hline & & case A & case B \\
\hline 2.47 & -55 & -51 & -53 \\
\hline $\begin{array}{c}1(2.401- \\
2.423)\end{array}$ & -56 & -54 & -56 \\
\hline $\begin{array}{c}2(2.406- \\
2.428)\end{array}$ & -57 & -55 & -56 \\
\hline $\begin{array}{c}3(2.411- \\
2.433)\end{array}$ & -57 & -54 & -56 \\
\hline $\begin{array}{c}4(2.416- \\
2.438)\end{array}$ & -53 & -51 & -53 \\
\hline $\begin{array}{c}5(2.421- \\
2.443)\end{array}$ & -54 & -51 & -53 \\
\hline $\begin{array}{c}6(2.426- \\
2.448)\end{array}$ & -53 & -51 & -52 \\
\hline $\begin{array}{c}7(2.431- \\
2.453)\end{array}$ & -53 & -52 & -53 \\
\hline $\begin{array}{c}8(2.436- \\
2.458)\end{array}$ & -55 & -50 & -52 \\
\hline $\begin{array}{c}9(2.441- \\
2.463)\end{array}$ & -53 & -49 & -52 \\
\hline $\begin{array}{c}10(2.446- \\
2.468)\end{array}$ & -55 & -49 & -52 \\
\hline $\begin{array}{c}11(2.451- \\
2.473)\end{array}$ & -54 & -51 & -53 \\
\hline
\end{tabular}




\section{CONCLUSION}

This article has proposed a dual-band switched beam antenna for WLAN users. This single patch can operate dual frequency bands, $2.47 \mathrm{GHz}$ and $5.04 \mathrm{GHz}$, and is capable of beam switching for two different directions. Beam pattern can be switched by shorted-circuits at edges of the patch. Its beamswitching capability has been confirmed through simulation and measurement. Moreover, the antenna is tested under real circumstances having a WLAN operation to confirm the improvement in performance of both frequencies. The advantages of the proposed antenna are that it is a simple structure, easy to perform beam switching and it can operate dual-band on only a single patch.

TABLE IV

THE MEASURED Signal StRENGTH AT $5.04 \mathrm{GHz}$

\begin{tabular}{cccc}
\hline \hline & \multicolumn{3}{c}{ Signal Strength } \\
\cline { 2 - 4 } Position & $\begin{array}{c}\text { Thni- } \\
\text { directional } \\
\text { antenna }\end{array}$ & case A & case B \\
\cline { 2 - 4 } & $\mathbf{- 6 5}$ & $\mathbf{- 6 0}$ & $\mathbf{- 6 0}$ \\
\hline 1 & $\mathbf{- 6 5}$ & -60 & $\mathbf{- 5 8}$ \\
2 & $\mathbf{- 6 6}$ & $\mathbf{- 6 0}$ & -62 \\
3 & $\mathbf{- 6 1}$ & $\mathbf{- 5 3}$ & $-\mathbf{4 9}$ \\
5 & $\mathbf{- 6 4}$ & $\mathbf{- 5 2}$ & -54 \\
6 & $\mathbf{- 8 4}$ & $\mathbf{- 7 2}$ & -77 \\
\hline \hline
\end{tabular}

TABLE V

The Measured Signal Strength of EACH Channel at $5.04 \mathrm{GHz}$

\begin{tabular}{cccc}
\hline \hline & \multicolumn{3}{c}{ Signal Strength } \\
Channel & \multicolumn{3}{c}{ The proposed antenna } \\
\cline { 2 - 4 }$(\mathrm{GHz})$ & $\begin{array}{c}\text { omni- } \\
\text { directional } \\
\text { antenna }\end{array}$ & case A & case B \\
\cline { 3 - 4 } & $\mathbf{- 5 1}$ & $\mathbf{- 4 5}$ & $\mathbf{- 4 5}$ \\
\hline $149(5.735$ & $\mathbf{- 5 0}$ & -46 & $\mathbf{- 4 4}$ \\
$-5.755)$ & & $\mathbf{- 4 5}$ & -47 \\
$153(5.755$ & $\mathbf{- 5 4}$ & $\mathbf{- 4 5}$ & $\mathbf{- 4 5}$ \\
$-5.775)$ & $\mathbf{- 5 3}$ & & \\
$157(5.775$ & $-5.795)$ & & \\
$161(5.795$ & & & \\
$-5.815)$ &
\end{tabular}

TABLE VI

FREQUENCY SPECTRUM AT 5.04 GHZ AND EACH CHANNEL USING SPECTRUM ANALYZER

\begin{tabular}{cccc}
\hline \hline & \multicolumn{3}{c}{ Signal Power $(\mathrm{dBm})$} \\
\cline { 2 - 4 } $\begin{array}{c}\text { Frequency } \\
(\mathrm{GHz})\end{array}$ & $\begin{array}{c}\text { omni- } \\
\text { directional } \\
\text { antenna }\end{array}$ & The proposed antenna \\
\cline { 2 - 4 } & -52 & -47 & case B \\
\hline 5.04 & -50 & -45 & -49 \\
$149(5.735$ & -53 & -46 & -47 \\
$-5.755)$ & & -47 & -49 \\
$153(5.755$ & -53 & -48 & -50 \\
$-5.775)$ & & & \\
$157(5.775$ & -52 & & \\
$-5.795)$ & & & \\
$161(5.795$ & & & \\
$-5.815)$ & &
\end{tabular}

\section{REFERENCES}

[1] A. Alexiou, and M. Haardt, "Smart antenna technologies for future wireless system,” IEEE Comm., Mag 42, 2004, pp. 90-97.

[2] P. Sooksumrarn, and M. Krairiksh, "A dual-band dual-feed switchedbeam single patch antenna," Proceeding of the Asia-Pacific Microwave Conference APMC, 2007.

[3] J. Tangapanij, P. Sooksumrarn, T. Tantisopharak, S. Janin, and M. Krairihsh, "A dual-band dual-feed switched-beam patch antenna for WLAN application," IEICE Transactions on Communications, Vol. E91B, No. 6, 2008, pp. 1791-1799.

[4] A. Pal, A. Mehta, and D. Mirshekar-Syahkal, "Dual band low-profile switched beam square loop antenna with capacitively coupled feeds," Proceeding of the 8th European Conference on Antennas and Propagation EuCAP, 2014, pp. 2578-2582.

[5] A. Pal, A. Mehta, D. Mirshekar-Syahkal, P. Deo, and H. Nakano, "Dualband low-profile capacitively coupled beam-steerable square-loop antenna," IEEE Transactions on Antennas and Propagation, Vol. 62, No. 3, 2014, pp. 1204-1211.

[6] A. Pal, A. Mehta, D. Mirshekar-Syahkal, and H. Nakano, "A low-profile switched-beam dual-band capacitively coupled square loop antenna," Proceeding of the Loughborough Antennas \& Propagation Conference, 2013, pp. 563-566.

[7] P. Ngamjanyaporn, C. Phongcharoenpanich, P. Akkaraekthalin, and M. Krairiksh, "Signal-to-Interference Ratio improvement by using a phased array antenna of switched-beam elements." IEEE Transactions on Antennas and Propagation, Vol. 53, No.5, 2005, pp. 1819-1828.

[8] M. Uthansakul, P. Chaipanya, and P. Uthansakul, "Performance evaluation of a low-cost switched-beam antenna for WLAN users," Microwave and Optical Technology Letters, Vol. 52, No. 9, 2010, pp. 2069-2074. 